\title{
Fas and Fas Ligand Gene Mutations in Hashimoto's Thyroiditis
}

\author{
Zhiming Dong, Tetsuya Takakuwa, Hitoshi Takayama, Wen-Juan Luo, Toru Takano, \\ Nobuyuki Amino, Fumio Matsuzuka, and Katsuyuki Aozasa \\ Departments of Pathology (ZD, T. Takakuwa, HT, W-JL, KA) and Laboratory Medicine (T. Takano, NA), Osaka \\ University Graduate School of Medicine, Suita, and the Section of Surgery, Kuma Hospital (FM), Kobe, Japan
}

SUMMARY: To clarify whether Fas and Fas ligand (FasL) mutations are involved in the pathogenesis of Hashimoto's thyroiditis $(\mathrm{HT})$, we examined the open reading frame of Fas and Fas $L$ in 21 cases. Mutations of Fas and Fas $L$ genes were detected in 8 $(38.1 \%)$ and $1(4.8 \%)$ of 21 cases, respectively. All but one of the Fas mutations were frameshift mutations, which affect the cytoplasmic region (death domain) known to be involved in apoptotic signal transduction and thus could be loss-of-function mutations. Fas $L$ mutation in one case was a 46-bp deletion from nucleotide 349 to 394, which corresponded to exon 2 . Lack of exon 2 results in a frameshift, which generates a stop codon at residue 128. This mutant encodes the protein that contains only a part of the intracellular domain, thus the abnormal protein might not be expressed on the cell surface. The cells with Fas mutations were confined to the mantle zone and the germinal center, as determined by microdissection methods. These findings suggest that the cells with Fas mutations might accumulate in those areas and might be involved in the pathogenesis of Hashimoto's thyroiditis. (Lab Invest 2002, 82:1611-1616).

$F_{\text {a }}^{\text {a }}$ as (Apo-1/CD95) is a $45-\mathrm{kDa}$ membrane protein $F$ belonging to the TNF receptor family and mediates programmed cell death (apoptosis) upon trimerization induced by cross-linking by Fas ligand (FasL) (Nagata and Golstein, 1995; Suda et al, 1993). FasL is a type II membrane protein that belongs to the TNF family (Suda et al, 1993). The Fas/FasL system regulates a number of physiologic and pathologic processes of cell death (apoptosis) including immune responses. For example, activated T cells expressing both Fas and FasL undergo suicide, kill each other, or kill the Fas-expressing activated $\mathrm{B}$ cells, resulting in down-regulation of the immune reaction. Failure of apoptosis, or programmed cell death, is considered to contribute to the development of autoimmune diseases through impaired elimination of autoreactive T or B cells. FasL is one of the major effector molecules of cytotoxic lymphocytes (CTL). Therefore, it is possible that CTLmediated tissue damage takes place through abnormal activation of FasL- or Fas-mediated apoptosis.

Hashimoto's thyroiditis (HT) is a well-known organspecific autoimmune disease and results in hypofunction in severe cases. Apoptosis of thyrocytes is occasionally observed in histologic sections of normal thyroid tissues and is accelerated during the pathologic processes, with destructive changes in the thy-

\section{DOI: 10.1097/01.LAB.0000041700.09232.9C}

Received September 13, 2002.

Supported by grants from the Ministry of Education, Science and Culture, Japan (12576004, 12670159, 1270159, 1277087, 14031213).

Address reprint requests to: Dr. K. Aozasa, Department of Pathology (C3), Osaka University Medical School, 2-2 Yamada-oka, Suita, Osaka 5650871,Japan.E-mail:aozasa@molpath.med.osaka-u.ac.jp roid gland, thus resulting in clinical hypothyroidism (Kotani et al, 1995; Mitsiades et al, 1998; Okayasu et al, 1995; Tanimoto et al, 1995). Fas expression and death signaling in thyrocytes have been demonstrated in HT (Giordano et al, 1997; Hammond et al, 1997; Mitsiades et al, 1998). Therefore, one hypothesis is that the thyrocytes expressing Fas are targets for CTL expressing FasL. Recent studies suggests that thyrocytes may kill themselves by constitutive expression of FasL and Fas, which are induced by IL-1 $\beta$ or IFN- $\gamma$ secreted by infiltrating immune cells (De Maria and Testi, 1998; Giordano et al, 1997). Alternatively, the thyrocytes expressing FasL in combination with other molecules known to be induced by inflammatory cytokines that can increase cell-to-cell contact (intercellular adhesion molecule, lymphocyte function-associated antigen, MHC II) may act as a defense mechanism and lead to specific killing of the invading immune cell, thus providing an immune-privileged status to the thyroid (Dayan et al, 1997). Therefore, a defect of FasL may allow invasion of the immune cells in the thyroid.

Pathoepidemiologic study showed that thyroid lymphoma arise in the activated lymphoid cells infiltrating in the HT (Aozasa et al, 1986; Volpe, 1975). Recently we have reported that mutations of the Fas gene were detected in $65.4 \%$ of thyroid lymphoma but occasionally in HT, although the number of samples examined was relatively small (Takakuwa et al, 2001). These findings raise a possibility that lymphoid cells with Fas mutations accumulate in the HT, providing a basis for development of thyroid lymphoma.

In this study, we extensively examined the Fas and FasL mutations in HT to clarify whether Fas/FasL mutations are involved in the pathogenesis of $\mathrm{HT}$. 
Mutations of Fas and FasL genes were detected in 8 $(38.1 \%)$ and $1(4.8 \%)$ of 21 cases, respectively. Subsequently, we specified the location of cells with Fas mutations, with the use of a microdissection method.

\section{Results}

\section{Mutations of the Fas Gene}

Mutations of the Fas gene were detected in 8 (38.1\%) of 21 cases of HT (Table 1). All but one of the mutations were frameshift mutations and affected the death domain. Fas gene has a 6-(A) tract from nucleotides 1088 to 1094 of the Fas cDNA sequence (GeneBank accession no. M67454) (Itoh et al, 1991), and four cases of HT had 7-(A) tract as a result of a 1 -bp insertion of $(A)$ into nucleotide 1095. Mutations in these cases occurred in the death domain known to be involved in the apoptotic signal transduction and thus could be loss-of-function mutations.

Three cases showed a 25-bp deletion from nucleotides 846 to 870 , which corresponded to exon 8. Lack of exon 8 results in a frameshift, which generates a stop codon at residue 205. As a result, the whole intracytoplasmic death domain is deleted (Cascino et al, 1996). Mutations in the acceptor splice site of Fas intron 7 or in the donor splice site of intron 8 might generate a splice variant of transcripts lacking exon 8 . To examine this hypothesis, genomic DNA from the patients was amplified using primers flanking exon 8, cloned, and then sequenced. One case (Case 5) had mutations in the consensus sequence of the acceptor splice site of intron 7 and one (Cases 3) had the donor splice site of intron 8, although it is not certain whether these mutations cause exon skipping (data not shown). Mutations could not be detected in the other case (Case 4).

\section{Mutation of FasL Gene}

Mutation of the FasL gene was detected in 1 (4.8\%) of 21 cases (Case 9). This case showed a 46-bp deletion from nucleotides 349 to 394 (Fig. 1) (Suda et al, 1993; Takahashi et al, 1994), which corresponded to exon 2. Lack of exon 2 results in a frameshift, which generates a stop codon at residue 128 . This mutant encodes the

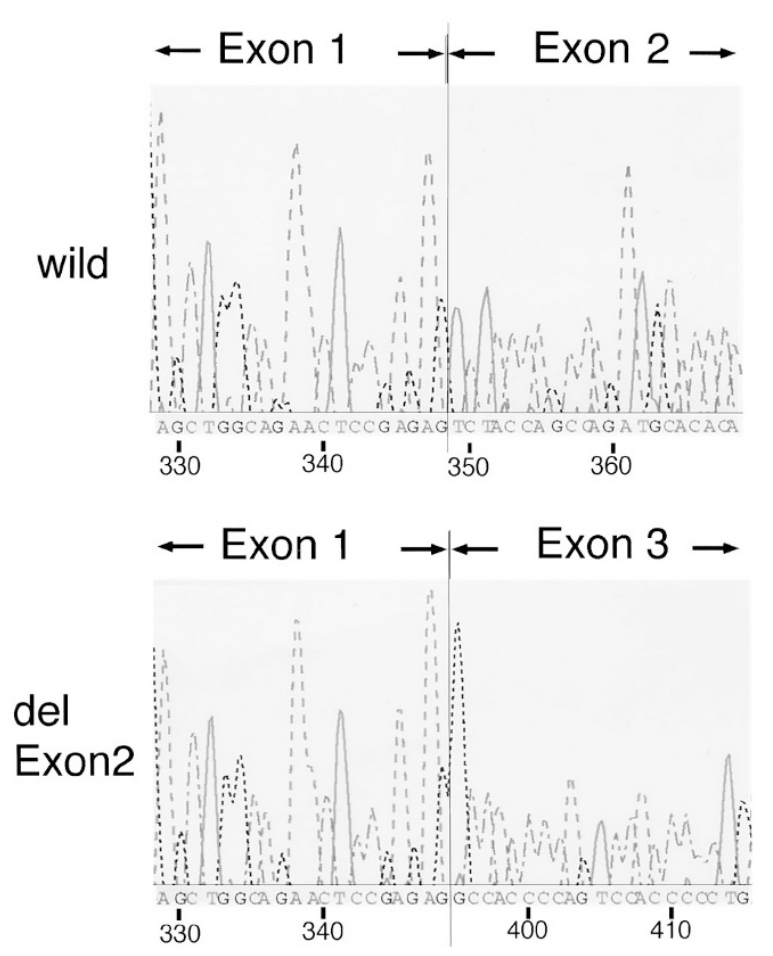

Figure 1.

Sequence of FasL gene cDNA derived from Case 9, showing a 46-bp deletion from nucleotides 349 to 394 , which corresponds to exon 2.

protein that contains only a part of cytoplasmic domain, thus the abnormal protein might not be expressed on the cell surface. Frequency of mutations among clones was $40 \%$. To examine whether mutations in the acceptor splice site of FasL intron 1 or in the donor splice site of intron 2 might generate splice variants of transcripts lacking exon 2, genomic DNA from Case 9 was amplified using primers flanking exon 2 , cloned, and then sequenced. However, no mutations could be detected in that sequence (data not shown).

\section{Localization of Fas Gene Mutations}

Three to five lesions from each histologic area (ie germinal centers, mantle zones, interfollicular areas,

Table 1. Fas Mutations in Hashimoto's Thyroiditis

\begin{tabular}{|c|c|c|c|c|c|c|c|}
\hline No. & Age & Gender & Nucleotide change & Localization & Codon & Predicted effect & $\begin{array}{c}\text { Frequencies of } \\
\text { mutation-positive } \\
\text { clones }(\%)\end{array}$ \\
\hline 1 & 59 & $\mathrm{~F}$ & A416G & Exon 3 & 59 & Silent & 66.6 \\
\hline 2 & 70 & $\mathrm{~F}$ & $851 \mathrm{del} A G$ & Exon 8 & 203 & Frameshift (stop 208) & 43.8 \\
\hline 3 & 67 & $\mathrm{~F}$ & $846-870 \mathrm{del}$ (exon 8) & Exon 8 & $202-210$ & Frameshift (stop 204) & 34.4 \\
\hline 4 & 65 & $\mathrm{~F}$ & $846-870$ del (exon 8) & Exon 8 & $202-210$ & Frameshift (stop 204) & 9.4 \\
\hline \multirow[t]{2}{*}{5} & 67 & $\mathrm{~F}$ & $846-870 \mathrm{del}$ (exon 8) & Exon 8 & $202-210$ & Frameshift (stop 204) & 9.4 \\
\hline & & & 1095 ins $A$ & Exon 9 & 285 & Frameshift (stop 303) & 9.4 \\
\hline 6 & 66 & $\mathrm{~F}$ & 1095 ins $A$ & Exon 9 & 285 & Frameshift (stop 303) & 6.3 \\
\hline 7 & 52 & $\mathrm{~F}$ & 1095 ins $A$ & Exon 9 & 285 & Frameshift (stop 303) & 37.5 \\
\hline 8 & 56 & $\mathrm{~F}$ & 1095 ins $A$ & Exon 9 & 285 & Frameshift (stop 303) & 9.4 \\
\hline
\end{tabular}

F, female; del, deletion; ins, insertion. 
and thyroid follicles) were selected for microdissection. Fas gene mutations were detected only in the mantle zones in two cases and in both the germinal centers and mantle zones in another two cases (Table 2). Fas mutations were never detected in the interfollicular areas and thyroid follicular epithelium.

\section{Clinical and Histologic Findings}

Serum thyroglobulin levels in HT patients with and without Fas mutations were $132.6 \pm 253.1 \mathrm{ng} / \mathrm{ml}$ and $476.2 \pm 571.0 \mathrm{ng} / \mathrm{ml}$, respectively. Serum thyroid stimulating hormone and FT4 levels were within normal ranges in most of the cases. There were no significant differences in the serum levels of antithyroglobulin and antimicrosomal antibody between HT cases with and without Fas mutation. Germinal centers were hyperplastic in 3 of 8 Fas-mutated cases (Cases 2, 3, and 7) and in 1 of 13 cases without mutations. The degree of lymphocytic infiltration and fibrosis in the thyroid tissue was not significantly different between cases with and without Fas mutation.

\section{Discussion}

Fas-mediated apoptosis is a sophisticated mechanism for regulation of cell death and plays an important role in normal tissue development and homeostasis as well as in disease processes. A defect in apoptosis caused by abnormalities in the Fas/FasL system allows survival of autoreactive lymphocytes, which might result in systemic autoimmunity. Indeed patients who carry inherited defects in Fas and FasL genes exhibit a similar, albeit variable, pattern of phenotypes, including systemic lupus erythematosus (SLE), which have been collectively termed autoimmune lymphoproliferative syndrome (Drappa et al, 1996; Fisher et al, 1995; Nagata, 1998; Rieux-Laucat et al, 1995). An important role of Fas in SLE has been suggested from the observation that $60 \%$ of patients with SLE showed elevated levels of soluble Fas receptor in their serum (Cheng et al, 1994; Kovacs et al, 1997). Abundant soluble Fas receptor in the serum may protect lymphocytes from undergoing apoptosis, although this remains a subject of controversy (Goel et al, 1995; Knipping et al, 1995). Wu et al (1996) reported that a FasL defect is not a major factor contributing to the pathogenesis of SLE.

In the present study, mutations of the Fas gene were detected in 8 of 21 cases, suggesting that Fas gene mutations might play a role in the pathogenesis of HT. All but one of the Fas mutations were frameshift mutations, which affect the cytoplasmic region (death domain) known to be involved in the apoptotic signal transduction and thus could be loss-of-function mutations. In fact we have shown that mouse T-cell lymphoma cells transfected with frameshift mutations caused by insertion of a 1-bp (A) at nucleotide 1095 (as observed in Cases 5, 6, 7, and 8) were resistant to apoptosis induced by the anti-Fas antibody (Takakuwa et al, 2002). Deletion of exon 8 as a splicing variant of the Fas gene has been reported in the apoptosis-resistant clone, which was derived from human T-cell lymphoma cell line HUT78 (Cascino et al, 1996). The frameshift mutation found in Case 2 (851 del AG) might be a loss-of-function mutation because it generate a stop codon at residue 205. As a result, the whole intracytoplasmic death domain is deleted, which is equivalent to the deletion of exon 8. Only one case (Case 2) showed mutations of the Fas $L$ gene; this mutant gene encodes a protein that contain only a part of cytoplasmic domain, thus the abnormal protein might not be expressed on the cell surface. It is not clear whether the FasL mutation in this case contributed to the pathogenesis of HT.

Analysis of genomic DNA microdissected from the HT lesions showed that cells with Fas gene mutations were confined to the mantle zone and less frequently the germinal center. Thyrocytes and lymphoid cells outside the lymphoid follicles did not show Fas gene mutations. Although cytotoxic T cells and thyrocytes are reported to express FasL and kill Fas-expressing cells in HT (Giordano et al, 1997; Mitsiades et al, 1998), lymphocytes with Fas mutations may survive and accumulate in the tissues.

The majority of lymphocytes in the germinal center and mantle zone are of B-cell origin. Our previous study showed that the lymphomas arising from HT are of B-cell origin and showed frequent Fas mutations (Takakuwa et al, 2001). These findings suggest that Fas gene mutations occur among the $\mathrm{B}$ cells in the lymphoid follicles, which might provide a basis for development of lymphoma. Recent studies showed that expression of functional Fas on B cells is essential for the regulation of autoantibody production (Fukuyama et al, 1998; Shinohara et al, 1997). Therefore, unless the autoreactive or activated B cells are killed through the interaction of Fas expressed on the $B$-cell surface and FasL expressed on the activated $T$ cells, these activated $B$ cells might continue to pro-

Table 2. Localization of Cells with Fas Gene Mutations

\begin{tabular}{|c|c|c|c|c|c|}
\hline \multirow[b]{2}{*}{ Case } & \multirow[b]{2}{*}{ Age/gender } & \multicolumn{4}{|c|}{ Number of mutations per examined area } \\
\hline & & Germinal center & Mantle zone & Interfollicular area & Thyroid follicle \\
\hline 5 & $67 / F$ & 0/192 (4) & $5 / 176(5)$ & 0/144 (3) & 0/144 (3) \\
\hline 6 & $66 / F$ & $0 / 104(3)$ & $1 / 128(4)$ & $0 / 128(4)$ & $0 / 128(4)$ \\
\hline 7 & $52 / F$ & $2 / 272(5)$ & $5 / 144(4)$ & $0 / 160(4)$ & $0 / 148(4)$ \\
\hline 8 & $56 / F$ & $2 / 220(4)$ & $4 / 86(3)$ & $0 / 160(4)$ & $0 / 128(4)$ \\
\hline
\end{tabular}

The number of areas examined are shown in parentheses. 
duce autoantibodies. Taken together, B lymphocytes with Fas mutations in the lymphoid follicles of HT become resistant to the apoptosis induced by the Fas/FasL system and continue to produce thyroid autoantibodies, which destroy the thyroid follicular epithelium.

It is also possible that cells other than B cells in the lymphoid follicles carry the Fas mutations. Autoreactive $\mathrm{T}$ cells might remain alive in thyroid tissue as a result of Fas mutations and provide helper signals necessary for B-cell proliferation and differentiation. These activated B cells might overproduce the autoantibodies. Future studies will examine which subsets carry the Fas mutation and whether the presence of cells with Fas mutations is involved in the pathogenesis of HT.

In conclusion, the present results suggest that mutations of Fas occur in lymphoid cells but not thyrocytes of HT. FasL mutations are infrequent both in thyrocytes and lymphocytes. These findings indicate that further study on lymphoid follicles formed in the thyroid gland of HT may provide insight on the disease mechanism of HT.

\section{Patients and Methods}

\section{Cases}

Thyroid specimens were collected from 21 patients with HT. They were admitted to Kuma Hospital (Kobe City, Japan) with varying degrees of goiter from 1995 to 2001. All but two cases were women, with age at admission ranging from 45 to 70 (median 66) years. All patients underwent surgery including total or partial thyroidectomy or open biopsy, and the histologic specimens were fixed in $10 \%$ formalin and routinely processed for paraffin embedding. Histologic sections cut at 4- $\mu \mathrm{m}$ thickness were stained with hematoxylin and eosin and were reviewed for histologic diagnosis. Samples in all cases were snap-frozen with optimal cutting temperature compound at $-150^{\circ} \mathrm{C}$ and stored at $-80^{\circ} \mathrm{C}$ until use. Criteria for the diagnosis of HT included increased consistency of the thyroid gland, occasional hypothyroidism, a high level of thyroid stimulating hormone, low ${ }^{123}$ I uptake, and the presence of antimicrosomal and/or antithyroglobulin antibodies in the serum. Histologic findings of HT included lymphocytic infiltration, usually forming lymphoid follicles with germinal centers, varying degrees of fibrosis, and oxyphilic change or squamous metaplasia of epithelial cells of the thyroid follicles. The presence of these clinical and histological parameters was compared between cases with and without Fas mutations.

\section{Isolation of Total RNA, RT-PCR, and Detection of Mutations}

Fresh-frozen samples from HT were homogenized, and total RNA was extracted in the presence of TRIzol reagent (GIBCO BRL, Grand Island, New York). Five micrograms of total RNA was reverse-transcribed by random hexamer priming, and $1 \mu \mathrm{g}$ was subjected to PCR as a template. The open reading frames of Fas and FasL were amplified using the oligonucleotide primers Fas-F, -R and FasL-F, -R, respectively (Table 3). Thermocycling conditions for each reactions were 35 cycles of denaturation at $94^{\circ} \mathrm{C}$ for 15 seconds, annealing at the various temperatures shown in Table 3 for 15 seconds, and extension at $72^{\circ} \mathrm{C}$ for 1 minute, followed by a final 7 -minute extension at $72^{\circ} \mathrm{C}$. PCR products were purified using the QIAquick PCR Purification Kit (Qiagen, Studio City, California), and cloned in PCR 2.1-TOPO according to the indications of the manufacturer (Invitrogen, San Diego, California). Sequencing was performed using the DNA sequencing kit (Applied Biosystems, Foster City, California) and analyzed by the Genetic Analyzer (ABI PRISM 310'; Applied Biosystems). Twelve to 16 clones derived from two different $\mathrm{PCR}$ reactions were sequenced. When common mutations were found in two $\mathrm{PCR}$, we regarded them as definite mutations. Frequency of clones with Fas mutations among clones sequenced was defined as frequency of mutationpositive clones.

Table 3. Oligonucleotide Primers Used for PCR Reactions

\begin{tabular}{|c|c|c|c|}
\hline & Primer sequence & $\operatorname{Ta}\left({ }^{\circ} \mathrm{C}\right)$ & PCR products (bp) \\
\hline \multicolumn{4}{|c|}{ cDNA primers } \\
\hline Fas-F & 5'-CACTTCGGAGGATTGCTCAACA-3' & 54 & 1,163 (nt. 170-1336) \\
\hline Fas-R & 5'-TATGTTGGCTCTTCAGCGCTA-3' & & \\
\hline FasL-F & 5'-TGACTCACCAGCTGCCATGCAG-3' & 54 & 886 (nt. 170-1336) \\
\hline FasL-R & 5'-GGAAAGAATCCCAAAGTGCTTCTC-3' & & \\
\hline \multicolumn{4}{|c|}{ Genomic primers } \\
\hline $8-\mathrm{F}$ & 5'-ATTAAGGAAAAATTAGAAGTTCACATT-3' & 52 & 217 \\
\hline $8-\mathrm{R}$ & 5'-ATCCCATAATATGTCACTGAAA-3' & & \\
\hline 9-F1 & 5'-GAAAGTTCAACTGCTTCGTAATTGG-3' & 50 & 102 \\
\hline $9-R$ & 5'-GCAAGAGTACAAAGATTGG-3' & & \\
\hline $9-\mathrm{F} 2$ & 5'-CTTCGTAATTGGCATCAACTTCAT-3' & 50 & 89 \\
\hline $2-\mathrm{F}$ & 5'-TTTATTTGACGATTCTGCCTCTTTTT-3' & 50 & 186 \\
\hline $2-\mathrm{R}$ & 5'-TAACATAGTTCTGTGCTGAGGAT-3' & & \\
\hline
\end{tabular}

Ta, annealing temperature; nt, nucleotides. 


\section{Detection of Mutations in the Exon/Intron Boundary of Fas Exon 8 and FasL Exon 2}

Cases 3, 4, and 5 had deletions in exon 8 of the Fas gene, and Case 9 had a deletion in exon 2 of the Fas $L$ gene. Genomic DNA extracted from the frozen tissues of these cases were subjected to PCR with the oligonucleotide primers, $8 \mathrm{~F}$ and $8 \mathrm{R}$, and $2 \mathrm{~F}$ and $2 \mathrm{R}$ (Table 3), which flank Fas exon 8 and FasL exon 2, respectively. PCR products were cloned in PCR 2.1-TOPO (Invitrogen). Twenty-four clones were sequenced.

\section{Laser Capture Microdissection and DNA Extraction}

Thyroid tissues in patients with HT contain lymphocytic infiltration, usually forming lymphoid follicles with germinal centers. To specify which kind of histologic lesions have Fas mutations, microdissection was performed on the paraffin-embedded samples of the selected cases (Cases 5, 6, 7, and 8) with an insertion (A) at nucleotide 1095 of the Fas gene. Lymphoid cells in the germinal centers, mantle zones, interfollicular areas, and thyroid follicular epithelium, all in the HT lesions, were microdissected with the use of a PixCell laser capture microscope (Arcturus Engineering, Santa Clara, California) according to previously described methods with some modifications (Bonner et al, 1997; Emmert et al, 1996). Briefly, histologic sections were dehydrated and then the histologic fields of interest were selected, overlaid with a thermoplastic film mounted on a transparent cap, and captured by film through laser energy. The dissected pieces were allowed to adhere to the transparent cap and were collected in 0.5-ml Eppendorf tubes. The procured cells were subsequently resuspended in 20 to $50 \mu$ l of extraction buffer containing $10 \mathrm{~mm}$ Tris ( $\mathrm{pH}$ 8.0), $2 \mathrm{~mm}$ EDTA, $0.2 \%$ Tween 20, and $200 \mu \mathrm{g} / \mathrm{ml}$ proteinase $\mathrm{K}$ and were incubated overnight at $37^{\circ} \mathrm{C}$. The mixture was heated at $100^{\circ} \mathrm{C}$ for 10 minutes to inactivate the proteinase $\mathrm{K}$, and a $3 \%$ to $5 \%$ of solution was used for a template for each PCR.

\section{Detection of a 1-bp (A) Insertion at Nucleotide 1095 of Fas Exon 9}

Genomic DNA extracted by microdissection methods from cases $5,6,7$, and 8 were subjected to PCR with the oligonucleotide primers, 9F1 and 9R (Table 3), which flank the 6-(A) tract from nucleotides 1088 to 1094 of the Fas cDNA sequence of Fas exon 9. PCR products were cloned in pCR 2.1-TOPO (Invitrogen). Thirty-two to 96 bacterial colonies were subjected to PCR as a template using the oligonucleotide primers, 9F2 and 9R. To detect the difference of $1 \mathrm{bp}$ as a result of insertion, reaction products $(3 \mu \mathrm{l})$ were denatured and separated on $8 \%$ polyacrylamide gels containing $8 \mathrm{M}$ urea. The gels were analyzed with FMBIO-II (Takara, Kusatsu, Japan).

\section{References}

Aozasa K, Inoue A, Tajima K, Miyauchi A, Matsuzuka F, and Kuma K (1986). Malignant lymphomas of the thyroid gland:
Analysis of 79 patients with emphasis on histologic prognostic factors Cancer 58:100-104.

Bonner RF, Emmert BM, Cole K, Pohida T, Chuaqui R, Goldstein S, and Liotta LA (1997). Laser capture microdissection: Molecular analysis of tissue. Science 278: 1481-1483.

Cascino I, Papoff G, De Maria R, Testi R, and Ruberti G (1996). Fas/Apo-1 (CD95) receptor lacking the intracytoplasmic signaling domain protects tumor cells from Fasmediated apoptosis. J Immunol 156:13-17.

Cheng J, Zhou T, Liu C, Shapiro JP, Brauer MJ, Kiefer MC, Barr PJ, and Mountz JD (1994). Protection from Fasmediated apoptosis by a soluble form of the Fas molecule. Science 263:1759-1762.

Dayan CM, Elsegood KA, and Maile R (1997). FasL expression on epithelial cells: The Bottazzo-Feldman hypothesis revisited. Immunol Today 18:203.

De Maria R and Testi R (1998). Fas-FasL interactions: A common pathogenetic mechanism in organ-specific autoimmunity. Immunol Today 19:121-125.

Drappa J, Vaishnaw AK, Sullivan KE, Chu JL, and Elkon KB (1996). Fas gene mutations in the Canale-Smith syndrome, an inherited lymphoproliferative disorder associated with autoimmunity. N Engl J Med 335:1643-1649.

Emmert BM, Bonner RF, Smith PD, Chuaqui RF, Zhuang Z, Goldstein SR, Weiss RA, and Liotta LA (1996). Laser capture microdissection. Science 274:998-1001.

Fisher GH, Rosenberg FJ, Straus SE, Dale JK, Middleton LA, Lin AY, Strober W, Lenardo MJ, and Puck JM (1995). Dominant interfering Fas gene mutations impair apoptosis in a human autoimmune lymphoproliferative syndrome. Cell 81:935-946.

Fukuyama H, Adachi M, Suematsu S, Miwa K, Suda T, Yoshida N, and Nagata S (1998). Transgenic expression of Fas in T cells blocks lymphoproliferation but not autoimmune disease in MRL-Ipr mice. J Immunol 160:3805-3811.

Giordano C, Stassi G, De Maria R, Todaro M, Richiusa P, Papoff G, Ruberti G, Bagnasco M, Testi R, and Galluzzo A (1997). Potential involvement of Fas and its ligand in the pathogenesis of Hashimoto's thyroiditis. Science 275:960963.

Goel N, Ulrich DT, St Clair EW, Fleming JA, Lynch DH, and Seldin MF (1995). Lack of correlation between serum soluble Fas/APO-1 levels and autoimmune disease. Arthritis Rheum 38:1738-1743.

Hammond LJ, Lowdell MW, Cerrano PG, Goode AW, Bottazzo GF, and Mirakian R (1997). Analysis of apoptosis in relation to tissue destruction associated with Hashimoto's autoimmune thyroiditis. J Pathol 182:138-144.

Itoh $\mathrm{N}$, Yonehara $\mathrm{S}$, Ishii $\mathrm{A}$, Yonehara $\mathrm{M}$, Mizushima $\mathrm{S}$, Sameshima M, Hase A, Seto $Y$, and Nagata S (1991). The polypeptide encoded by the cDNA for human cell surface antigen Fas can mediate apoptosis. Cell 66:233-243.

Knipping E, Krammer PH, Onel KB, Lehman TJ, Mysler E, and Elkon KB (1995). Levels of soluble Fas/APO-1/CD95 in systemic lupus erythematosus and juvenile rheumatoid arthritis. Arthritis Rheum 38:1735-1737.

Kotani T, Aratake Y, Hirai K, Fukazawa Y, Sato H, and Ohtaki $S$ (1995). Apoptosis in thyroid tissue from patients with Hashimoto's thyroiditis. Autoimmunity 20:231-236. 
Kovacs B, Szentendrei T, Bednarek JM, Pierson MC, Mountz JD, Vogelgesang SA, and Tsokos GC (1997). Persistent expression of a soluble form of Fas/APO1 in continuously activated T cells from a patient with SLE. Clin Exp Rheumatol 15:19-23.

Mitsiades N, Poulaki V, Kotoula V, Mastorakos G, Tseleni BS, Koutras DA, and Tsokos M (1998). Fas/Fas ligand upregulation and $\mathrm{Bcl}-2$ down-regulation may be significant in the pathogenesis of Hashimoto's thyroiditis. J Clin Endocrinol Metab 83:2199-2203.

Nagata S (1998). Human autoimmune lymphoproliferative syndrome, a defect in the apoptosis-inducing Fas receptor: A lesson from the mouse model. J Hum Genet 43:2-8.

Nagata S and Golstein P (1995). The Fas death factor. Science 267:1449-1456.

Okayasu I, Saegusa M, Fujiwara M, Hara Y, and Rose NR (1995). Enhanced cellular proliferative activity and cell death in chronic thyroiditis and thyroid papillary carcinoma. J Cancer Res Clin Oncol 121:746-752.

Rieux-Laucat F, Le Deist F, Hivroz C, Roberts IA, Debatin KM, Fischer A, and de Villartay J (1995). Mutations in Fas associated with human lymphoproliferative syndrome and autoimmunity. Science 268:1347-1349.

Shinohara N, Ikegami Y, Yokoyama M, Yonehara S, and Komano H (1997). Prevention of autoantibody production in Ipr/lpr mice by transgenic expression of Fas on B cells. Ann N Y Acad Sci 815:489-491.
Suda T, Takahashi T, Golstein P, and Nagata S (1993). Molecular cloning and expression of the Fas ligand, a novel member of the tumor necrosis factor family. Cell 75:11691178.

Takahashi T, Tanaka M, Inazawa J, Abe T, Suda T, and Nagata S (1994). Human Fas ligand: Gene structure, chromosomal location and species specificity. Int Immunol 6:1567-1574.

Takakuwa T, Dong Z, Nakatsuka S, Kojya S, Harabuchi Y, Yang WI, Nagata S, and Aozasa K (2002). Frequent mutations of Fas gene in nasal NK/T cell lymphoma. Oncogene 21: 4702-4705.

Takakuwa T, Dong Z, Takayama H, Matsuzuka F, Nagata S, and Aozasa K (2001). Frequent mutations of Fas gene in thyroid lymphoma. Cancer Res 61:1382-1385.

Tanimoto C, Hirakawa S, Kawasaki H, Hayakawa N, and Ota Z (1995). Apoptosis in thyroid diseases: A histochemical study. Endocr J 42:193-201.

Volpe R (1975). Thyroiditis: Current views of pathogenesis. Med Clin North Am 59:1163-1175.

Wu J, Wilson J, He J, Xiang L, Schur PH, and Mountz JD (1996). Fas ligand mutation in a patient with systemic lupus erythematosus and lymphoproliferative disease. J Clin Invest 98:1107-1113. 